\title{
ANALISIS PERENCANAAN OVERLAY PADA RUAS JALAN CRAKEN-NGULUNGKULON NAMBAK-NGULUNGKULON DENGAN BAHAN ACL PADA STA 0.00-13.345 KECAMATAN MUNJUNGAN KABUPATEN TRENGGALEK
}

\author{
Wisnu Arganata*1, Artur Daniel Limantara ${ }^{2}$, Yosef Cahyo SP ${ }^{3}$, Agata Iwan Candra ${ }^{4}$. \\ ${ }^{1,2,3}$ Fakultas Teknik, Universitas Kadiri. \\ e-mail:*1 Wisnuarganata@gmail.com,22arthurlimantara@gmail.com, \\ ${ }^{3}$ yosef.cs@unik-kediri.ac.id, ${ }^{4}$ iwan candra@unik-kediri.ac.id.
}

\begin{abstract}
Nowadays, the development of road capacity and vehicle quantity and the lack of optimal traffic infrastructure operations are the main problems in the Nambak-Ngulungkulon Craken-Ngulungkulon road section. This road is the object of observation because the road is an integrated system of the NambakNgulungkulon Craken-Ngulungkulon road network. It is necessary to analyze how the performance and the thickness of the flexible pavement layer needed. To analyze road performance and calculate pavement thickness, the writer uses the Bina Marga 2017 method with ACL material at STA 0.00 - 13,345. The results of the analysis and calculation for the geometric planning of the Nambak-Ngulungkulon CrakenNgulungkulon road section obtained the value of surface course with the 2017 Bina Marga method of 13 $\mathrm{cm}$. Overlay work on the planning age is carried out in the 15 the year with an additional layer thickness with the Bina Marga 2017 method of $3 \mathrm{~cm}$. And the traffic growth rate increased by $28.65 \%$ for 10 years y.a.d.
\end{abstract}

Keywords : ACL, Highways, Overlay, Traffic Growth.

\begin{abstract}
Abstrak
Saat ini pengembangan kapasitas jalan dan kuantitas kendaraan dan kurangnya operasi infrastruktur lalu lintas yang optimal adalah masalah utama di ruas jalan Nambak-Ngulungkulon Craken-Ngulungkulon. Jalan ini adalah objek pengamatan karena jalan tersebut merupakan sistem yang terintegrasi dari jaringan jalan Nambak-Ngulungkulon Craken-Ngulungkulon. Perlu untuk menganalisis bagaimana kinerja dan ketebalan lapisan perkerasan lentur yang dibutuhkan. Untuk menganalisis kinerja jalan dan menghitung tebal perkerasan, penulis menggunakan metode Bina Marga 2017 dengan material ACL di STA 0,00 13,345. Hasil analisis dan perhitungan untuk perencanaan geometrik ruas jalan Nambak-Ngulungkulon Craken-Ngulungkulon diperoleh nilai permukaan jalan dengan metode Bina Marga $201713 \mathrm{~cm}$. Pekerjaan overlay pada usia perencanaan dilakukan pada tahun ke-15 dengan tambahan ketebalan lapisan dengan metode Bina Marga $20173 \mathrm{~cm}$. Dan tingkat pertumbuhan lalu lintas meningkat sebesar 28,65\% selama 10 tahun y.a.d.
\end{abstract}

Kata Kunci : ACL, Bina Marga, Overlay, Pertumbuhan Lalulintas. 


\section{PENDAHULUAN}

Jaringan jalan merupakan sarana transportasi darat yang memegang peranan penting dalam sektor perhubungan, terutama untuk kesinambungan distribusi barang dan jasa [1][2][3]. Ketersediaan jalan yang memadai dengan kondisi yang baik, lancar, aman, nyaman, dan efisien sangat diperlukan untuk menunjang laju pertumbuhan ekonomi[4]. Seiring dengan meningkatnya kebutuhan sarana transportasi yang dapat menjangkau daerah-daerah yang merupakan pusat potensi ekonomi [5]. Kota Trenggalek, khususnya kecamatan Munjungan merupakan jalur yang menghubungkan ke arah Kota Pacitan dan mempunyai peranan penting sebagai daerah pertumbuhan ekonomi dan industri, [6][3][7]. Daerah ini mempunyai tanggung jawab untuk menata kembali wilayahnya termasuk meningkatkan sarana trasnportasi dalam hal ini jalan raya, sehinga tidak timbul kemacetan dan kecelakaan lalu lintas, akan tetapi dapat memberikan suasana yang tertib, nyaman, aman dan lancar dalam berlalu lintas yang menuju antar kota, selain dari pada itu pendistribusian barang dan jasa lebih mudah [8][9][10].

\section{METODE PENELITIAN}

\subsection{Lokasi Penelitian.}

Penelitian ini dilakukan di ruas jalan Craken-Ngulungkulon Nambak-Ngulungkulon Kecamatan Munjangan Kabupaten Trenggalek.

\subsection{Analisis Lalulintas}

Dengan asumsi awal Snawal $=3,3$ dan $\mathrm{Pt}=2,0$ diperoleh faktor ekivalen masing-masing kendaraan seperti pada tabel berikut :

Tabel 1. Faktor Ekivalen Kendaraan menurut Metode Bina Marga 2017 Jenis Kendaraan Faktor Ekivalen

\begin{tabular}{|l|c|}
\hline \multicolumn{1}{|c|}{ Jenis Kendaraan } & Faktor Ekivalen \\
\hline GOL 1 & 0,0008 \\
\hline GOL 2 & 0,1672 \\
\hline GOL 3 & 0,8029 \\
\hline GOL 4 & 1,0865 \\
\hline GOL 5 & 1,1389 \\
\hline
\end{tabular}

Sumber : [11][12] Bina Marga 2017

Pada Tabel 1. Diketahui jenis kendaraan Gol 1 memiliki Faktor Ekivalen 0,0008, Gol 2 memiliki Faktor Ekivalen 0,1672, Gol 3 memiliki Faktor Ekivalen 0,8029, Gol 4 memiliki Faktor Ekivalen 1,0865, Gol 5 memiliki Faktor Ekivalen 1,1389 
Tabel 2. Jumlah Kendaraan Ekivalen 18 kip ESAL

\begin{tabular}{|c|c|c|c|c|c|}
\hline $\begin{array}{c}\text { Jenis } \\
\text { Kendaraan }\end{array}$ & $\begin{array}{l}\text { Jumlah } \\
\text { Kendaran } \\
\text { Tahun } 1 \\
\text { (a) }\end{array}$ & $\begin{array}{c}\begin{array}{c}\text { Angka } \\
\text { Pertumbuhan }\end{array} \\
6 \% \\
\text { (b) }\end{array}$ & $\begin{array}{l}\text { Perencanaan } \\
\text { Tahun } 1 \\
\text { (c) }=(a) x(b)\end{array}$ & $\begin{array}{c}\text { Faktor } \\
\text { Ekivalen } \\
\text { (d) }\end{array}$ & $\begin{array}{l}\text { Perencanan } \\
\text { 18-K ESAL } \\
\text { (e) }=\text { (c) } x(\text { d })\end{array}$ \\
\hline GOL 1 & $12.838,00$ & 36,79 & $472.310,02$ & 0,0008 & 377,8480 \\
\hline GOL 2 & 441,00 & 36,79 & $16.224,39$ & 0,1672 & $2.712,7180$ \\
\hline GOL 3 & $2.457,00$ & 36,79 & $90.393,03$ & 0,8029 & $72.576,5638$ \\
\hline GOL 4 & 296,00 & 36,79 & $10.889,84$ & 1,0865 & $11.831,8112$ \\
\hline GOL 5 & 148,00 & 36,79 & $5.444,92$ & 1,3819 & $7.524,3349$ \\
\hline Total & $16.180,00$ & & $595.262,20$ & $\begin{array}{c}18 \mathrm{k}- \\
\text { ESAL } \\
\text { (W18) }\end{array}$ & $95.023,2759$ \\
\hline
\end{tabular}

Sumber : Data diolah

Keterangan :

(a) = Jumlah LHR awal tahun perencanaan

(b) = Faktor pertumbuhan lalulintas $\quad$ : faktor $=(1+g)-1 g$

Dimana $: g=\frac{\text { angka pertumbuhan lalulintas }}{100}$

Pengulangan kumulatif 18- kip ESAL per-arah pada lajur rencana tahun pertama :

$\mathrm{W} 18 \mathrm{t}=\mathrm{DD} \times \mathrm{DL} \times \mathrm{W} 18$

Dimana :

$\mathrm{DD}=$ faktor distribusi arah $50 \%$

$\mathrm{DL}=$ Faktor distribusi lajur $100 \%$

Maka :

$$
\begin{aligned}
\mathrm{W} 18 \mathrm{t} & =0,5 \cdot 1 \cdot 95 \cdot 023,2759 \\
& =17511,637018-\mathrm{kip} \text { ESAL } \\
& =0,5 \cdot 10^{\wedge} 618-\mathrm{kip} \text { ESAL }
\end{aligned}
$$

Untuk menentukan pengulangan beban dalam perencanaan fungsi waktu dibuat gambar perkiraan kumulatif pengulangan 18 -kip ESAL dalam periode analisis, yang diperoleh dari persamaan :

$W 18 t=W 18^{\prime}[(1+g)-1 g]$

Dimana :

$\mathrm{W} 18 \mathrm{t}=$ kumulatif pengulangan 18-kip ESAL perarah pada lajur rencana fungsi waktu

$\mathrm{W} 18^{\prime}=$ kumulatif pengulangan 18-kip ESAL pada tahun pertama

$\mathrm{g}=$ angka pertumbuhan lalulintas $6 \%$

$\mathrm{t}=$ waktu (tahun perencanaan) 
Tabel 3. Kumulatif 18-kip ESAL terhadap waktu

\begin{tabular}{|c|c|c|c|}
\hline $\begin{array}{c}\text { Waktu } \\
\text { (Tahun) } \\
\text { X }\end{array}$ & $\begin{array}{c}\text { Kumulatif Beban } \\
\text { Ekivalen } \\
\text { Y }\end{array}$ & $\begin{array}{c}\text { Waktu } \\
\text { (Tahun) } \\
\text { X }\end{array}$ & $\begin{array}{c}\text { Kumulatif Beban } \\
\text { Ekivalen } \\
\text { Y }\end{array}$ \\
\hline 0 & 0,0000 & 5 & 281854,6479 \\
\hline 1 & 47511,6380 & 6 & 348765,9268 \\
\hline 2 & 103000,0000 & 7 & 419691,8824 \\
\hline 3 & 159180,0000 & 8 & 494873,3954 \\
\hline 4 & 218773,0800 & 9 & 574565,7991 \\
\hline
\end{tabular}

\section{Sumber : Hasil Perhitungan}

Pada Tabel 3. Menunjukkan nilai Kumulatif Beban Ekivalen dari tahun ke tahun mulai tahun ke 1 sampai tahun ke 9 .

\subsection{Pengaruh Pengembangan Tanah Dasar}

Pengaruh pengembangan tanah dasar menyebabkan berkurangnya tingkat pelayanan dan dihitung berdasarkan : ketebalan badan jalan $=46 \mathrm{~cm} \quad$; Indek plastisitas $=12$; Potensi pengembangan vertikal $(\mathrm{Vr})=0,32$ inchi dan Swell Rate Constant $(\Theta)=0,07$ untuk PI $>20$

Jadi pengaruh pengembangan tanah dasar adalah :

$\triangle$ PSISW $=0,00335 . \mathrm{Vr} . \mathrm{Ps} .\left(1-\mathrm{e}^{\wedge}-\Theta \mathrm{t}\right)$

Dibuat gambar $\triangle \mathrm{PSISW}$ fungsi waktu, dengan Ps $=80 \%$ (timbunan tanah dasar disumsikan mempunyai swelling yang sama). Hasil perhitungnan $\triangle$ PSISW terdapat pada tabel di bawah berikut :

Tabel 4. Hasil Perhitungan Pengaruh Pengembangan Tanah Dasar

\begin{tabular}{|c|c|c|c|}
\hline $\begin{array}{c}\text { Waktu } \\
\text { Tahun } \\
\mathrm{X}\end{array}$ & $\begin{array}{c}\Delta \text { PSISW } \\
\mathrm{Y}\end{array}$ & $\begin{array}{c}\text { Waktu } \\
\text { (Tahun) } \\
\mathrm{X}\end{array}$ & $\begin{array}{c}\Delta \text { PSISW } \\
\mathrm{Y}\end{array}$ \\
\hline 0 & 0.0000 & 10.5 & 0,0252 \\
\hline 1 & 0.0012 & 11 & 0.0264 \\
\hline 1.5 & 0.0036 & 11.5 & 0.0276 \\
\hline 2 & 0.0048 & 12 & 0.0288 \\
\hline 2.5 & 0.0060 & 12.5 & 0.0300 \\
\hline 3 & 0.0072 & 13 & 0.0312 \\
\hline 3.5 & 0.0084 & 13.5 & 0.0324 \\
\hline 4 & 0.0096 & 14 & 0.0336 \\
\hline 4.5 & 0.0108 & 14.5 & 0.0348 \\
\hline 5 & 0.0120 & 15 & 0.0360 \\
\hline 5.5 & 0.0132 & 15.5 & 0.0372 \\
\hline 6 & 0.144 & 16 & 0.0384 \\
\hline 6.5 & 0.156 & 16.5 & 0.0396 \\
\hline 7 & 0.0168 & 17 & 0.0408 \\
\hline 7.5 & 0.0180 & 17.5 & 0.0420 \\
\hline 8 & 0.0192 & 18 & 0.0432 \\
\hline
\end{tabular}




\begin{tabular}{|c|c|c|c|}
\hline 8.5 & 0.0204 & 18.5 & 0.0444 \\
\hline 9 & 0.0216 & 19 & 0.0456 \\
\hline 9.5 & 0.0228 & 19.5 & 0.0468 \\
\hline 10 & 0.0240 & 20 & 0.0480 \\
\hline
\end{tabular}

Sumber : Hasil Perhitungan

Pada Tabel4. Memperlihatkan hasil perhitungan pengaruh pengembangan tanah dasar tiap tahun serta nilai $\triangle$ PSISW

\subsection{Tahapan Penelitian.}

Adapun alur dan tahapan pada penelitian ini secara garis besar adalah Pengamatan awal, setelah itu lanjut untuk Studi literatur, kemudian membuat Rumusan masalah, kemudian melakukan Pengumpulan data dan Pelaksanaan survei. Setelah itu Pengolahan data yang terakhir Pembahasan serta Kesimpulan..

\section{HASIL DAN PEMBAHASAN}

\subsection{Analisis Perhitungan Tebal Perkerasan Dengan Mtode Bina Marga 2017}

Data-data yang dipergunakan dalam perhitungan ini diambil dari Proyek Jalan CrakenNgulungkulon Nambak-Ngulungkulon, kondisi jalan masih berupa jalan terjal, sedangkan untuk data lalu lintas berpatokan pada Manual Kapasitas Jalan Indonesia (MKJI) 1997, [13][14] dan material lapis perkerasan diambil data fiktif.

Perhitungan tebal lapis perkerasan jalan dengan metode Bina Marga 2017, [15][16] dihitung berdasarkan tabel data-data berikut :

Data -data lain yang diperlukan adalah :

1. Periode analisis : 10 tahun

2. Angka pertumbuhan lalulintas : $6 \%$

3. Fungsi jalan : Urban

4. Klasifikasi jalan : Arteri

5. Tanah dasar (CBR) : $8 \%$

6. Indek Plastisitas (IP) : 12,00

Data - data yang diasumsikan :

1. Tingkat Pelayanan awal (Po) : 4,2 (lapis permukaan beton aspal)

2. Keandalan $(\mathrm{R})$

a. Jalan arteri urban diambil : $90 \%$

b. Untuk 2 tahab (perkerasan awal dan 1 kali overlay), $R=0,9^{\wedge 1 / 2}: 95 \%$

c. $\mathrm{Zr}$ (simpangan baku normal) untuk $\mathrm{R}=95 \%:-1,645$

3. Koefisien drainase (m) 
a. diambil 0,8 untuk keadaan drainase cukup dan waktu pengeringan dalam keadaan lembab sampai jenuh > $25 \%$

b. Standar Deviasi keseluruhan (So) Untuk perencanaan antara 0,4 -0,5 diambil So $=$ 0,45

c. Tanah dasar $(\mathrm{Mr}=$ Modulus resilien $)$

$\mathrm{Mr} \quad=1500 \times \mathrm{CBR}$

$$
\begin{aligned}
& =1500 \times 8 \\
& =12.000 \mathrm{Psi}
\end{aligned}
$$

\subsection{Perencanaan Tebal lapis Perkerasan}

Untuk konstruksi perkerasan jalan dengan umur 20 tahun dipakai pendekatan analisis lapisan yang digunakan untuk menentukan ketebalan lapisan, [17][18][19]. Konstruksi perkerasan jalan terdiri atas 3 lapis yaitu:

1. Lapis permukaan beton aspal (ACL) $: \mathrm{E}=40000 \mathrm{Psi} ; \mathrm{a} 1=0,42$

2. Lapisan pondasi atas, batu pecah kelas $\mathrm{A}: \mathrm{E}=30000 \mathrm{Psi} ; \mathrm{a} 2=0,14$

3. Lapisan pondasi bawah agregat kelas $\mathrm{B}: \mathrm{E}=11000 \mathrm{Psi} ; \mathrm{a} 3=0,08$

Penentuan ketebalan masing-masing lapisan adalah :

a. Lapis permukaan : $\mathrm{R}=95 \%$; $\mathrm{So}=0,45$; W20 = 1,8 x 10^6 18-kip ESAL

b. Lapis pondasi atas : $\mathrm{E}=30000 \mathrm{Psi} ; \mathrm{PSITR}=2,1532 ; \mathrm{SN}=2,1$

\section{Ketebalan beton aspal :}

$$
\begin{aligned}
\mathrm{D}^{*} 1 & =\mathrm{SN} 1 / \mathrm{a} 1=2,1 / 0,42 \\
& =5 \mathrm{inchi}=12,7 \mathrm{~cm} \approx 13 \mathrm{~cm} \text { atau } 5,118 \mathrm{inchi} \\
\mathrm{SN}^{*} & =\mathrm{a} 1 . \mathrm{D} * 1=0,42.5,118 \\
& =2,148>\mathrm{SN} 1=2,1
\end{aligned}
$$

\section{Lapis pondasi atas :}

Dengan data yang sama kecuali $\mathrm{E}=11000$ Psi diperoleh SN2 $=2,90$

Ketebalan batu pecah kelas A (CBR $80 \%)$ :

$$
\begin{aligned}
\mathrm{D} * 2 & =\mathrm{SN} 2-\mathrm{SN} * 1 /(\mathrm{a} 2 \mathrm{~m} 2) \\
& =2,9-2,149 /(0,14 \cdot 0,8) \\
& =6,705 \text { inch } \\
& =17,03 \mathrm{~cm} \approx 17,5 \text { atau }=6,9 \text { inch } \\
\mathrm{SN} * 2 & =\mathrm{a} 2 \cdot \mathrm{D} * 2 \mathrm{~m} 2 \\
& =0,14 \cdot 6,9 \cdot 0,8 \\
& =0,77
\end{aligned}
$$

$\mathrm{SN} * 1+\mathrm{SN} * 2>\mathrm{SN} 22,148+0,77=2,919>2,9$ 


\section{Lapis Pondasi Bawah :}

Ketebalan agregat kelas B (CBR $100 \%)$

$$
\begin{aligned}
\mathrm{D} * 3 & =[\mathrm{SN} 3-(\mathrm{SN} * 2+\mathrm{SN} * 1)] / \mathrm{a} 3 \mathrm{~m} 3 \\
& =[3,35-(0,77+2,148)] / 0,08.0,8 \\
& =6,734 \text { inch }=17,105 \mathrm{~cm} \approx 17,5 \mathrm{~cm} \text { atau }=6,9 \text { inch }
\end{aligned}
$$

SNtotal $=0,42 \cdot 5,118+0,14 \cdot 6,9 \cdot 0,8+0,08 \cdot 6,9 \cdot 0,8$

$$
=3,36
$$

\subsection{Hasil Stabilitas Marshal Test Lapis Permukaan}

$\operatorname{HRS}(843 \mathrm{~kg})=0,21$

ATBL $(746 \mathrm{~kg})=0,19$

$\operatorname{ATB}(1232 \mathrm{~kg})=0,255 .+$

Jumlah $\quad=0,655$

Hasil test mis design test :

1. Agregat base course kelas A (CBR $80 \%): a 2=0,13$

2. Agregat subbase kelas B (CBR $30 \%) \quad$ : a3 $=0,109$

Perhitungan tebal masing-masing lapis perkerasan dengan hasil stabilitas Marshal test adalah sebagai berikut :

\section{Lapis Permukaan :}

$$
\begin{aligned}
\mathrm{D}^{*} 1 & =\mathrm{SN} 1 / \mathrm{a} 1=2,1 / 0,655 \\
& =3,206 \text { inch }=8,14 \mathrm{~cm} \approx 8,5 \mathrm{~cm} \text { atau }=3,, 346 \text { inch } \\
\mathrm{SN}^{*} 1 & =\mathrm{a} 1 . \mathrm{D} 1=0,655.3,346 \\
& =2,1919>\mathrm{SN} 1=2,1
\end{aligned}
$$

\section{Lapis Pondasi Atas :}

$$
\begin{aligned}
& \mathrm{D} * 2=\mathrm{SN} 2-\mathrm{SN}^{*} 1 /(\mathrm{a} 2 \mathrm{~m} 2)=2,9-2,1919 /(0,13.0,8) \\
& =6,808 \text { inch }=17,29 \mathrm{~cm} \approx 17,5 \text { atau }=6,9 \text { inch } \\
& \mathrm{SN} * 2=\mathrm{a} 2 . \mathrm{D} * 2 \mathrm{~m} 2=0,13 \cdot 6,9 \cdot 0,8 \\
& =0,7176 \\
& \mathrm{SN} * 1+\mathrm{SN} * 2>\mathrm{SN} 2 \\
& 2,1919+0,7176=2,909>\mathrm{SN} 2=2,9
\end{aligned}
$$

\section{Lapis Pondasi Bawah :}

$$
\begin{aligned}
\mathrm{D} * 3 & =[\mathrm{SN} 3-(\mathrm{SN} * 2+\mathrm{SN} * 1)] / \mathrm{a} 3 \mathrm{~m} 3 \\
& =[3,35-(0,7176+2,1919)] / 0,109.0,8 \\
& =5,05 \mathrm{inch}=12,8 \mathrm{~cm} \approx 13 \mathrm{~cm} \text { atau }=5,12 \text { inch }
\end{aligned}
$$

SNtotal $=0,655 \cdot 3,346+0,13 \cdot 6,9 \cdot 0,8+0,109 \cdot 5,12 \cdot 0,8$ 


$$
=3,3556
$$

\subsection{Perhitungan Perkerasan Jalan Lama (Overlay) Metode Bina Marga 2017}

Perhitungan pekerjaan jalan lama atau overlay dengan metode Bina Marga 2017 dengan menggunakan data - data berikut [16][20]:

1. Laston (ACL) : a1 =0,445 (tebal $13 \mathrm{~cm})$

2. Lapis pondasi atas kelas $\mathrm{A}(\mathrm{CBR} 80 \%): \mathrm{a} 2=0,13($ tebal $17,5 \mathrm{~cm})$

3. Lapis pondasi bawah kelas $B(C B R 30 \%): a 3=0,109$ (tebal $17,5 \mathrm{~cm}$ )

4. CBR tanah dasar : $9,1 \%$ - So : $0,45-\mathrm{R}: 95 \%$

5. $\mathrm{Mr}=1500 \times \mathrm{CBR}=1500 \times 9,1=13650$

Berdasarkan data-data diatas diperoleh nilai SN sebesar 3,5

Perhitungan tebal lapis perkerasan tambahan (overlay) adalah :

1. $60 \% \cdot 13 \cdot 0,455=3,471 \mathrm{~cm}$

2. $100 \% \cdot 17,5 \cdot 0,13=2,275 \mathrm{~cm}$

3. $100 \% \cdot 17,5 \cdot 0,109=1,9075 \mathrm{~cm}+\Sigma \mathrm{SN}=7,6535 \mathrm{~cm}$ atau 3,013 inch $\mathrm{SN}-\Sigma \mathrm{SN} \quad=0,455 . \mathrm{D} 1$

D1 $=1,0944$ inch atau $2,779 \mathrm{~cm} \approx 3 \mathrm{~cm}$

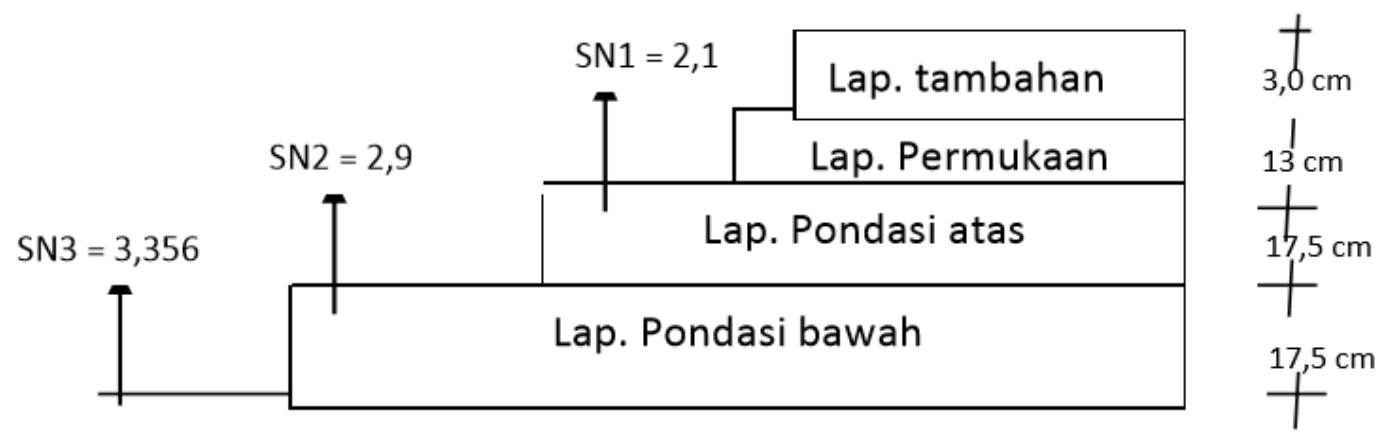

Gambar 3.1 : Tebal tambahan lapis perkerasan dengan Metode Bina Marga 2017

\section{KESIMPULAN}

Dari perencanaan peningkatan ruas jalan Craken - Ngulungkulon ; Nambak Ngulungkulon dengan lebar perkerasan yang ada $4.00 \mathrm{~m}$ dan panjang p13.456 km dapat disimpulkan sebagai berikut :

1. Dari hasil perhitungan diketahui nilai tebal lapis permukaan (surface course) dengan metode Bina Marga 2017sebesar $13 \mathrm{~cm}$.

2. Pekerjaan lapisan tambahan (overlay) pada umur rencana dilakukan pada tahun ke 15 dengan tebal lapis tambahan dengan metode Bina Marga 2017sebesar $3 \mathrm{~cm}$. 
Angka pertumbuhan lalu lintas merupakan hal penting yang harus diperhatikan dalam perhitungan tebal perkerasan. Pada penelitian ini angka pertumbuhan lalulintas meningkat $28,65 \%$ untuk 10 tahun y.a.d.

\section{SARAN}

Peningkatan jalan ruas jalan craken-nglungkulon;nambak-ngulungkulon munjungan sebaiknya dilakukan perawatan secara berkala sehingga jalan dapat berfungsi selama umur rencana bahkan lebih.

\section{UCAPAN TERIMAKASIH}

Dalam penyusunan artikel ini, penulis ucapkan terimakasih kepada dosen pembimbing dan Universitas Kadiri. Penulis berharap agar artikel ini dapat bermanfaat bagi pembaca.

\section{DAFTAR PUSTAKA}

[1] R. Yuwono, Y. C. Sp, and L. D. K, "STUDY ANALISA VOLUME KENDARAAN PADA SIMPANG BERSINYAL DI PEREMPATAN ALUN ALUN KOTA KEDIRI,” Jurmateks, vol. 1, no. 1, pp. 101-111, 2018.

[2] H. Yustianingsih and Istianah, "SURVEI KEPADATAN ARUS LALU LINTAS DI PERSIMPANGAN PENCENG JALAN RA. RUKMINI, KECAPI KEBUPATEN JEPARA,” pp. 19-24, 2017.

[3] R. Rahman, “Analisa Dampak Lalu Lintas (Studi Kasus: Studi Kemacetan di Jalan Ngagel Madya Surabaya)," SMARTek, vol. 8, no. 4, pp. 317-332, 2010.

[4] A. Nashirudin, S. Winarto, and Sudjati, "PERENCANAAN CHECKDAM KALI NGASINAN KANAN DESA NOTOREJO KECAMATAN GONDANG KABUPATEN TULUNGAGUNG,” Jurmateks, vol. 1, no. 2, pp. 192-203, 2018.

[5] R. O. Purbawa, A. Ridwan, and Y. C. S. P, "PERENCANAAN STRUKTUR ATAS ASRAMA PUTRI DI UNIVERSITAS KADIRI,”Jurmateks, vol. 1, no. 2, pp. 182-191, 2018.

[6] A. D. Limantara, A. I. Candra, and S. W. Mudjanarko, "MANAJEMEN DATA LALU LINTAS KENDARAAN BERBASIS SISTEM INTERNET CERDAS KADIRI," semnastek, no. November, pp. 1-2, 2017.

[7] F. A. Lestari and Y. Apriyani, "ANALISIS DAMPAK LALU LINTAS AKIBAT ADANYA PUSAT PERBELANJAAN DIKAWASAN PASAR PAGI PANGKALPINANG TERHADAP KINERJA RUAS JALAN,” J. Fropil, vol. 2, no. 1, 
pp. 32-44, 2014.

[8] T. Y. Purnomo, L. D. Krisnawati, and Y. C. Sp, "KAJIAN JEMBATAN KECAMATAN SENDANG (RUAS JALAN TUGU - PABYONGAN) KABUPATEN TULUNGAGUNG DENGAN METODE KOMPOSIT," Jurmateks, vol. 1, no. 1, pp. 112$125,2018$.

[9] I. B. P. Widiarta, “Analisis Pemilihan Moda Untuk Perjalanan Kerja ( Studi Kasus : Desa Dalung, Kecamatan Kuta Utara, Badung, Bali ),” J. Ilm. Tek. Sipil, vol. 14, no. 2, pp. 218 $225,2010$.

[10] A. Kholiq, "Perencanaan Tebal Perkerasan Lentur Jalan Raya Antara Bina Marga Dan Aashto'93 (Studi Kasus: Jalan Lingkar Utara Panyingkiran-Baribis Ajalengka),” JEnsitec, vol. 1, no. 01, pp. 43-51, 2014, doi: 10.31949/j-ensitec.v1i01.15.

[11] Direktorat Jendral Bina Marga, "Tata Cara Perencanaan Geometrik Jalan Antar Kota." 2017.

[12] [Kementerian PUPR]. Kementerian Pekerjaan Umum dan Perumahan Rakyat direktorat jendral bina marga and D. J. B. Marga, "Manual Desain Perkerasan Jalan," Nomor 02/M/BM/2013, 2013.

[13] E. Kusnandar, "Manual Kapasitas Jalan Indonesia 1997," J. Jalan dan Jemb., vol. 26, no. 2, pp. 1-11, 2009.

[14] R. Fitriana, "STUDI KOMPARASI PERENCANAAN TEBAL PERKERASAN KAKU JALAN TOL MENGGUNAKAN METODE BINA MARGA 2002 DAN AASHTO 1993 ( Studi Kasus : Ruas Jalan Tol Solo - Kertosono )," J. Chem. Inf. Model., vol. 53, no. 9, pp. 1689-1699, 2013, doi: 10.1017/CBO9781107415324.004.

[15] Departeman Pekerjaan Umum Direktorat Jenderal Bina Marga, "Geometri Jalan Bebas Hambatan Untuk Jalan Tol," Standar Geom. Jalan Bebas Hambatan Untuk Jalan Tol, no. 010, 2009.

[16] Direktorat Jendral Bina Marga, "Perencanaan Geometrik Jalan," Departemen Pekerjaan Umum. 2017.

[17] A. Theofilatos, G. Yannis, E. I. Vlahogianni, and J. C. Golias, "Modeling the effect of traffic regimes on safety of urban arterials: The case study of Athens," J. Traffic Transp. Eng. (English Ed., vol. 4, no. 3, pp. 240-251, 2017, doi: 10.1016/j.jtte.2017.05.003.

[18] S. Awiyaningsih, H. Moetriono, and D. T. Sipil, "ANALISIS DAMPAK LALU LINTAS AKIBAT PEMBANGUNAN MALL LAGOON AVENUE SUNGKONO TERHADAP KINERJA SIMPANG DI JL MAYJEND SUNGKONO - HR MUHAMMAD SURABAYA," Tek. Eng. Sains J., vol. 2, no. 2, pp. 131-134, 2018.

[19] I. T. Husodo and S. Budirahardjo, "Analisa desain pelebaran perkerasan lentur pada jalan 
wolter monginsidi semarang," J. Tek. Sipil Giratory Upgris, vol. 1, no. 1, pp. 1-9, 2019.

[20] M. L. Pangerapan, T. K. Sendow, and L. Elisabeth, "Studi Perbandingan Perencanaan Tebal Lapis Tambah (Overlay) Perkerasan Lentur Menurut Metode Pd t-05- 2005-b dan Manual Desain Perkerasan Jalan 2013 (Studi Kasus : Ruas Jalan Bts . Kota Manado Tomohon),” J. Sipil Statik, vol. 6, no. 10, pp. 823-834, 2018. 